\title{
PSYCHOLOGICAL CO-MORBIDITIES AND ILLNESS MANAGEMENT AMONG PATIENTS WITH ULCERATIVE COLITIS
}

\section{Ghulam Ishaq', Hina Sultan ${ }^{2 \otimes}$}

\begin{abstract}
OBJECTIVES: To examine the frequencies of psychological co-morbidities among Ulcerative Colitis patients, and to also study relationship of these morbidities with aggression and self-efficacy.

METHODS: This descriptive, correlational study was conducted at outpatient department of gastroenterology of Mayo hospital Lahore, from 2nd April to 28th August, 2019. A purposive sample of I65 UC patients was taken. Following ethical approval, structured questionnaires including Beck Depression Inventory-21, Berrenberg's Cancer Attitude Inventory, Emet-Q, Blood-Injection Symptom Scale, Templer Death Anxiety Scale, Short form Aggression Questionnaire and SEMCD6, to measure psychological illnesses were administered. The collected data were evaluated through SPSS V25.0.
\end{abstract}

RESULTS: Out of 165 patients, 85 (5I.5\%) were females \& 80 (48.5\%) were males, with age range $2 \mathrm{I}-30$ years. Sixty five $(39.39 \%)$ had severe depression, 54 (32.72\%) had moderate, 23 (13.93\%) borderline and I 4 (8.48\%) mild depression. Carcinophobia was seen in 139 (84.24\%) patients whereas emetophobia, trypanophobia, and death anxiety was present in II 4 (69.09\%), 101 (6I.21\%), 78 (47.27\%) patients respectively. Depression and phobias were increasing the physical, verbal aggression, anger, and hostility. Additionally, the patients' high depressive state and fears were affecting the illness management.

CONCLUSION: UC patients manifest a range of psychological co-morbidities. Especially, fear of developing cancer and death anxiety, restrict patients to control symptoms, to manage role and emotional functioning and to communicate with doctors to get adequate treatment regimens. Therefore, the commencement of psychotherapeutic programs can be helpful for maintaining the psychological health of patients.

KEY WORDS: Ulcerative Colitis (MeSH); Depression (MeSH); Phobias (MeSH); Aggression (MeSH); Chronic Illness Management (MeSH).

THIS ARTICLE MAY BE CITED AS: Ishaq G, Sultan H. Psychological comorbidities and illness management among patients with ulcerative colitis. Khyber Med Univ J 2020; I2(4):288-93. DOI: 10.35845/kmuj.2020.20I44.

\section{INTRODUCTION}

$\bigcup^{\prime}$ Icerative colitis (UC) is an inflammatory bowel disease (IBD) that causes long-lasting inflammation and ulcers in digestive tract and affects the innermost lining of colon and rectum.' Proctitis, proctosigmoiditis, left-sided colitis are the moderate forms of UC, while extensive and Pan-colitis refer to severe forms of UC. ${ }^{2}$ IBD has been reported in 6.8 million people around the globe in 2017. In USA, the prevalence of UC cases were around 23.2/1,00000 persons per year since
2000-2018 and it was predicted that there will be $11 \%$ increase in IBD patients by the year 2025 with increased mortality rate that is quite alarming. The most recent statistics computed in 2019 on South Asian population living in UK, showed that incidence of UC was $20.5 / 1,00000$ in people of Indian origin and II.2/100000 in Pakistani origin. ${ }^{5}$ Though, the prevalence rate is comparatively less in Pakistan than other countries but unfortunately, this ratio is increasing compared to old statistics that was $0.5-1.1 / 100000$ individuals in last decade due to the
I. Department of Psychology, Lahore Leads University, Pakistan

2. Department of Applied Psychology, Lahore College for Women University, Lahore, Pakistan.

Email凶: hina.sultan91@yahoo.com Contact \#: +92-322-5903289

$\begin{array}{ll}\text { Date Submitted: } & \text { March 03, 2020 } \\ \text { Date Revised: } & \text { November 20, } 2020 \\ \text { Date Accepted: } & \text { November 21, } 2020\end{array}$

increased intake of junk food, caffeine consumption, alcohol, and smoking. ${ }^{6}$

Various Asian, European, and Western researches indicated that UC patients suffer from a range of symptoms including colon cramps, abdominal bloating, rectal bleeding, food pieces and mucus in stools, frequent diarrhea, dysplasia, vomiting, lesions, headaches, weight loss, and fever. The recurrent episodes are more painstaking and longlasting symptoms lead to severe complications gradually. ${ }^{7}$ In UK, researchers found that patients with UC have poor quality of life, which exaggerate symptoms among patients. ${ }^{8}$ In America, the major impact UC has on patients includes frequent disease manifestations, non-adherence to prescribed medication, and health related poor quality of life. ' In Pakistan, researchers specified that UC patients balanced psychological state is immensely important because stress and anxiety intensify the symptoms and create hurdles for getting proper treatment remedies. ${ }^{10}$ The similar findings were revealed by another study, conducted in Iran." Researchers found that patients with UC are at more risk of developing colorectal cancer ${ }^{12}$ that develop depression and anxiety among them; the onset of nausea and IV therapies can develop specific phobias and such psychological issues effect the self-efficacy to manage illness. ${ }^{13}$

However, the evaluated percentages of psychological morbidities among UC patients are outdated and specially there is dearth of literature available 
TABLE I: DESCRIPTIVE STATISTICS OF ULCERATIVE COLITIS PATIENTS

\begin{tabular}{|c|c|c|c|}
\hline \multicolumn{2}{|c|}{ Characteristics } & \multirow{2}{*}{$\begin{array}{c}\begin{array}{c}\text { Frequency } \\
(n=165)\end{array} \\
25\end{array}$} & \multirow{2}{*}{$\begin{array}{c}\text { Percentage } \\
15.2\end{array}$} \\
\hline \multirow{5}{*}{$\begin{array}{l}\text { Time span } \\
\text { of diagnosis }\end{array}$} & One year & & \\
\hline & Two years & 48 & 29.1 \\
\hline & Three years & 43 & 26.1 \\
\hline & Four years & 26 & 15.7 \\
\hline & Five years & 23 & 13.9 \\
\hline \multirow{5}{*}{$\begin{array}{l}\text { Extent of } \\
\text { disease }\end{array}$} & Proctitis & 39 & 23.6 \\
\hline & Proctosigmoiditis & 53 & 32.1 \\
\hline & Left-sided colitis & 56 & 33.9 \\
\hline & Extensive colitis & $\mathrm{II}$ & 6.7 \\
\hline & Pan colitis & 6 & 3.6 \\
\hline \multirow{4}{*}{$\begin{array}{l}\text { Dependent on } \\
\text { IV infusion }\end{array}$} & Twice a year & 76 & 46.1 \\
\hline & Thrice a year & 71 & 43.0 \\
\hline & Four times a year & 12 & 7.3 \\
\hline & Five times a year & 6 & 3.6 \\
\hline \multirow{6}{*}{ Symptoms } & Rectal bleeding & 160 & 96.9 \\
\hline & Mucus in feces & 157 & 95.2 \\
\hline & Abdominal cramps & 165 & 100.0 \\
\hline & Dyspepsia & 134 & 81.2 \\
\hline & Weight loss & 93 & 56.4 \\
\hline & Fatigue & 122 & 73.9 \\
\hline \multirow{3}{*}{$\begin{array}{l}\text { Socio } \\
\text { economic status }\end{array}$} & Lower class & 36 & 21.8 \\
\hline & Middle class & 99 & 60.0 \\
\hline & Upper class & 30 & 18.2 \\
\hline
\end{tabular}

TABLE II: FREQUENCY OF DEPRESSION AND PHOBIAS

\begin{tabular}{|c|c|c|c|}
\hline \multicolumn{2}{|r|}{ Variable } & $\begin{array}{c}\text { Frequency } \\
(n=165)\end{array}$ & Percentage \\
\hline \multirow{5}{*}{ Depression } & Normal & 9 & 5.45 \\
\hline & Mild & 14 & 8.48 \\
\hline & Borderline & 23 & 13.93 \\
\hline & Moderate & 54 & 32.72 \\
\hline & Severe & 65 & 39.39 \\
\hline \multirow{4}{*}{ Phobias } & Carcinophobia & 139 & 84.24 \\
\hline & Emetophobia (Vomit phobia) & 114 & 69.09 \\
\hline & Trypanophobia (Blood/injection phobia) & 101 & 61.21 \\
\hline & Death anxiety & 78 & 47.27 \\
\hline
\end{tabular}

addressing these issues. Hence, literature focuses on the physical issues of patients but psychological disturbances and mental health is not given much attention, especially in Pakistan. So, this study was planned to fill the gap in literature by emphasizing on psychological co-morbidities and its possible relationship with disease management among UC patients. The main objective of the study was to examine the frequencies and percentages of depression and phobias among patients. Consequently, depressive and fearful states (phobias) of patients were studied with aggression i.e., physical, verbal aggression, anger, and hostility and also with patients' selfefficacy skills to manage the chronic disease (UC).

\section{METHODS}

This descriptive, correlational study was conducted at outpatient department of gastroenterology of Mayo hospital Lahore, from $2^{\text {nd }}$ April to $28^{\text {th }}$ August, 2019.
Researchers decided to take a purposive sample of 200 participants but 35 questionnaires were discarded due to incomplete information. Thus, the final sample size comprised of 165 patients $(\operatorname{men}=80$, women $=85)$. Sample size was calculated by $G$ power (this software helps the researchers to calculate power for statistical tests like correlation), with $\alpha$ error $=.05$ and actual power $=0.95$.

Following ethical approval and administrative approval from the hospital, data was collected within 5 months. The inclusion criteria of the study involved selection of participants, diagnosed with mild to severe UC, and belonging to the age group $21-30$. The reason of taking this age group was that this is the actual time when young adults usually enjoy the springs of life, and constructively progress in all spheres of life. Unfortunately, recurrent relapses disrupt their daily activities as they also want to excel in different spheres of life just like their age-fellows (i.e., studies, getting employment, and taking decisions for marriage). They keep thinking about their future with upcoming severe physical complications and experience more anxiety than older adults. ${ }^{14}$ So, understanding the psychological difficulties of this age group could provide prolific findings. Further, participants diagnosed with UC from I-5 years were taken (Table I). Moreover, patients with co-morbidities such as cancer/diabetes/osteoporosis were excluded as researcher's main interest was just in UC patients. Also, married patients were excluded because conjugal status could make the data more ambiguous (i.e., children, inlaws, or spouse insolent behaviors, economic issues etc.).

Demographic Information Form: Participants were asked about their gender, age, marital status, social class, symptoms, time span and extent of the disease.

Beck Depression Inventory-2 I: During the 1960s, this inventory was developed to measure the symptoms of depression with significant alpha reliability 0.86 and $0.8 \mathrm{I}$ for clinical and non-clinical US sample respectively. The 
response format ranges from 0 -3. For the convenience of participants, Urdu translated version with significant alpha reliability $\alpha=.75$, was used for the current study. 15 Beck suggested the cut off scores for normal $(\mathrm{I}-\mathrm{I} 0)$, mild (II$16)$, borderline (17-20), moderate (2I$30)$, and severe depression ( $3 \mid-65)$.

Berrenberg's Cancer Attitude Inventory: Cancer phobia was measured by adapting 3 items: I) I am most afraid of cancer, 2) It makes me uncomfortable to think about cancer, and 3) I worry a lot about developing cancer. ${ }^{16}$ This inventory is a 41 -item measure of attitudes towards cancer but just three items were chosen as potentially evaluating cancer phobia. All items used a 5-point Likert response from 'strongly disagree' to 'strongly agree'. Researchers translated the required items in Urdu through forward and backward translation procedure.

Emet-Q: This scale was devised to measure the fear of vomit in normal and clinical sample, with response format I5. The questionnaire assesses a range of vomit fears like bodily sensations, to avoid people who may be look like sick, and to avoid places which can cause nausea or vomit (i.e., elevator, rides). Later, in 2013, researchers found out the psychometric properties of scale which resulted in 13 items with significant internal consistency 0.82 in clinical population. ${ }^{17}$ For the current study, we translated this scale in Urdu by using forward and backward translation procedure.

Blood-Injection Symptom Scale: Blood-injection symptom scale (BISS) was devised in Australia. The scale consists of 17 questions related to blood/injection fear that are answered dichotomously (yes and no). ${ }^{18}$ The reliability of the entire scale is 0.86 . For the current study, we translated this scale in Urdu by using forward and backward translation procedure.

Templer Death Anxiety Scale: In the 1970, this scale was developed to measure the extent of death anxiety people experience. The DAS consisted of 15 items, to be rated on a dichotomous scale of true/false. Later, this scale was translated in Urdu for normal and cardiac patients with significant reliability $0.88 .^{19}$

Short form Aggression Questionnaire: This questionnaire comprised of four factors was developed in 1992. Later, researchers ran factor analysis and reduced it to 12 items including 3 items for each subscale, physical, verbal, anger, and hostility. The alpha reliability ranged from $0.84-0.86 .{ }^{20}$ For the present study, researchers translated this short scale in Urdu to use it adequately.

SEM-CD6: An instrument named "SelfEfficacy for Managing Chronic Disease 6-items Scale" was developed by selecting 605 chronic patients from USA. The scale consisted of four domains including symptom control, role and emotional functioning and communicating with physicians. The alpha reliability of the scale was 0.91 . The scoring format ranged from $0-10$. In Pakistan, this scale was translated in Urdu with significant reliability 0.94 . $^{21}$

Procedure: Following all ethical requirements (taking permission form MS of hospital and consent by patients), the help of doctors was taken to identify the actual UC patients, diagnosed through colonoscopy or endoscopies. Participants were asked to encircle the options that best describe them. They did not report any difficulty in comprehending the questionnaires because each scale was in Urdu and culturally unbiased. After data collection, descriptive and Pearson correlation analysis was run via SPSS version 25.0 to calculate the results.

TABLE III: PEARSON CORRELATION BETWEEN DEPRESSION, PHOBIAS, DEATH ANXIETY, AGGRESSION AND SELF-EFFICACY SUBSCALES, MEANS, STANDARD DEVIATIONS, ALPHAS

\begin{tabular}{|c|c|c|c|c|c|c|c|c|c|c|c|c|c|}
\hline Variables & I & 2 & 3 & 4 & 5 & 6 & 7 & 8 & 9 & 10 & II & 12 & 13 \\
\hline I.D & ----- & $.57 *$ & $.43 *$ & $.49 *$ & $.62 *$ & $.30 *$ & $.45 *$ & $.36 *$ & $.34 *$ & $-.30 *$ & $-.36 *$ & $-.26 *$ & $-.37 *$ \\
\hline 2.CP & & ----- & $.66 *$ & $.78 *$ & $.62 *$ & $.40 *$ & $.56 *$ & $.60 *$ & $.65 *$ & $-.65 *$ & $-.58 *$ & $-.72 *$ & $-.69 *$ \\
\hline $3 . B / I$ & & & ----- & $.67 *$ & $.45 *$ & $.32 *$ & $.49 *$ & $.53 *$ & $.37 *$ & $-.45 *$ & $-.34 *$ & $-.53 *$ & $-.26 *$ \\
\hline 4. VP & & & & ----- & $.39 *$ & $.25 *$ & $.38 *$ & $.4 I^{*}$ & $.23 *$ & $-.5 I^{*}$ & $-.27 *$ & $-.48 *$ & $-.23^{*}$ \\
\hline 5. DA & & & & & ----- & $.26 *$ & $.44 *$ & $.31 *$ & $.20 *$ & $-.56 *$ & $-.78 *$ & $-.43 *$ & $-.45 *$ \\
\hline 6.PA & & & & & & ------ & $.44^{*}$ & $.26 *$ & .29* & $-.34 *$ & $-.44 *$ & $-.65 *$ & $-.76^{*}$ \\
\hline 7.VA & & & & & & & ----- & $.44 *$ & $.52 *$ & $-.68 *$ & $-.59 *$ & $-.53 *$ & $-.82 *$ \\
\hline 8.A & & & & & & & & $\begin{array}{l}---- \\
\end{array}$ & $.57 *$ & $-.34 *$ & $-.41 *$ & $-.52 *$ & $-.46 *$ \\
\hline $9 . \mathrm{H}$ & & & & & & & & & ---- & $-.50 *$ & -.5 I* & $-.69 *$ & $-.78 *$ \\
\hline I0.SC & & & & & & & & & & ----- & $.29 *$ & $.32 *$ & $.30 *$ \\
\hline II. RF & & & & & & & & & & & $\begin{array}{l}---- \\
\end{array}$ & $.19 *$ & $.36 *$ \\
\hline 12. EF & & & & & & & & & & & & ----- & $.26 *$ \\
\hline 13. TD & & & & & & & & & & & & & ------ \\
\hline$M(S D)$ & $\begin{array}{c}32.7 \\
(15.3)\end{array}$ & $\begin{array}{l}12.6 \\
(5.4)\end{array}$ & $\begin{array}{c}35.0 \\
(14.0)\end{array}$ & $\begin{array}{l}14.5 \\
(2.3)\end{array}$ & $\begin{array}{c}9.0 \\
(1.0)\end{array}$ & $\begin{array}{l}10.9 \\
(2.3)\end{array}$ & $\begin{array}{l}12.0 \\
(3.1)\end{array}$ & $\begin{array}{c}9.6 \\
(2.4)\end{array}$ & $\begin{array}{c}6.7 \\
(1.1)\end{array}$ & $\begin{array}{c}7.8 \\
(.13)\end{array}$ & $\begin{array}{c}9.2 \\
(2.4)\end{array}$ & $\begin{array}{c}6.5 \\
(.11)\end{array}$ & $\begin{array}{c}7.2 \\
(.09)\end{array}$ \\
\hline$\alpha$ & .72 & .65 & .91 & .76 & .82 & .62 & .76 & .56 & .49 & .43 & .51 & .46 & .66 \\
\hline
\end{tabular}

D: Depression; CP: Carcinophobia; B/l: Blood/lnjection; VP: Vomit Phobia; DA: Death Anxiety; PA: Physical Aggression; VA: Verbal Aggression; A: Anger; H: Hostility; SC: symptom control; RF: role Functioning; EF: Emotional Functioning; TD: 


\section{RESULTS}

The study sample consisted of 165 UC participants, divided into 80 (48.5\%) men and $85(51.5 \%)$ women, with an average age of $25.4+9.1$ years. The core findings with respect to descriptive and associations among study variables have been presented in table: I, which represents that out of 165 participants, there were $39(23.6 \%)$ proctitis, 53 (32.1\%) proctosigmoiditis, 56 (33.9\%) left-sided colitis, I I (6.7\%) extensive and 6 (3.6\%) pancolitis; diagnosed via colonoscopies. Majority of patients $(n=76 ; 46.1 \%)$ were dependent on intravenous therapy twice a year.

Majority of the patients $(n=65 ; 39.5 \%)$ had severe depression, followed by moderate depression $(n=54 ; 32.7 \%)$. The common phobias among UC patients were afraid of developing colorectal cancer $(n=139: 84.24 \%)$ and emetophobia (Vomit phobia) in II4 ( 69.09\%) cases (Table II).

Table III showed a significant positive association between depression and carcinophobia, $r=.57, p<.001$. Depression also had significant relationships with blood/injection $r=.43$, $\mathrm{p}<.00 \mathrm{I}$, and vomit phobia $\mathrm{r}=.49, \mathrm{p}$ $<.00 \mathrm{I}$ and also with death anxiety $r=.62$, $\mathrm{p}<.00 \mathrm{I}$. For aggression, depression was significantly positively related to physical $r=.30, p<.00 \mathrm{I}$; verbal aggression, $r=.45$, $\mathrm{p}<.00 \mathrm{I}$; anger, $\mathrm{r}=.36, \mathrm{p}<.00 \mathrm{I}$; and hostility, $r=.34, p<.001$. Participants' phobias were also found to be significantly positively associated with physical, verbal aggression, anger, and hostility. Specifically, carcinophobia had strong associations with subtypes of aggression compared to other phobias which were also relatively high. Further, there was an inverse association of depression with selfefficacy to manage chronic illness including symptom control, $r=-.30, p<.001$; role functioning, $r=-.36, p<.001$; emotional functioning, $r=-.26, p<.00 \mathrm{I}$ and capability to have useful communication with physician, $r=-.37, p<.001$. Likewise, different forms of phobias specially carcinophobia had strong inverse association with patients' management of chronic illness. Death anxiety also had inverse relationship with symptom control $r=-.56, p<.00 I$, role function $r=-.78$, emotional functioning $r=-.43, p<.001$, and talking to doctor $r=-.45, p$ $<.00 \mathrm{I}$.Table III also displayed the means, standard deviations and moderate to strong alpha reliabilities of the scales computed for the present research.

\section{DISCUSSION}

The present research investigated the psychological co-morbidities of UC patients. Outcomes revealed that $32.72 \%$ patients were having moderate and $39.39 \%$ had severe form of depression; inferring that most of the UC patients suffer from depression which aggravates their aggression levels (verbal, physical), anger, and hostility and declines their selfefficacy to control symptoms such as engaging in activities that overcome the fatigue, emotional distress, and reduce the need to visit doctors more than necessary. The outcomes of the study also suggested the relationship of depression with carcinophobia, trypanophobia, emetophobia, and death anxiety. These findings are quite interesting suggesting that disturbed psychological states increase fears and anxiety which are manifested in the form of restlessness, agitation, sweating, and heart palpitations. The results are aligned with many studies indicating that UC patients experience a range of mood disorders including depression and anxiety which effect their quality of life and ability to cope. ${ }^{22-24}$ but these researchers did not study specific phobias with UC so our findings are quite new and other researchers can further investigate these phenomena in diverse ways. Our outcomes also indicated that carcinophobia (fear of developing colorectal cancer) had been reported the most 139(84.2\%). Emetophobia was found among I I 4 (69.09\%) patients while $101(61.21 \%)$ were suffering from Trypanophobia (fear of blood/injections). Further, 78 (60.0\%) participants had death anxiety. While looking at these findings with previous literature, in United States, researchers found that UC, Crohn's disease and IBD patients are at highest risk of developing cancer ${ }^{25}$ so we speculated that UC patients might experience carcinophobia which also demonstrated among majority of the patients in the current study. Also, researchers found that patients suffering from any particular disease or experiencing any accidental event (cancer, diabetes, cardiovascular problems) generally develop blood/injection phobias which is associated with depression. ${ }^{26}$ Further, in another study, a strong relationship of blood/injection phobia in cancer patients taking IV therapy was seen, thus, indirectly supporting our results. ${ }^{27}$ In UK, a study revealed that UC patients usually have higher mortality rates that is $5.7 \%$ following 3 -year treatment. ${ }^{28}$ So, high mortalities caused by UC can also aggravate death anxiety. Our outcomes elaborated that phobias and death anxiety increase aggression and decrease the selfefficacy to manage chronic disease. Literature also shed light on patients with inflammatory bowel disease; explaining anxiety disorders restrict their abilities to manage the disease effectively. ${ }^{12}$ In Karachi (20।3), researchers indicated that 40 Dyspepsia patients recommended for endoscopy were having $82.5 \%, 60 \%$, and $60.7 \%$ anxiety, depression, and stress respectively, thus supporting our findings by showing that such kinds of diseases aggravate psychological problems. ${ }^{10} \mathrm{~A}$ few researchers conducted meta-analysis and found a considerable relationship of depression and anxiety with UC and inflammatory bowel disease among Native Americans, Russians, and Asians." As far as phobias and death anxiety among UC patients have been studied, the results of current study are quite new and adding new findings in literature. Especially, our findings demonstrated strong associations of carcinophobia with depression and aggression levels and also suggested the decreased ability to manage disease symptoms, emotions, and performing daily life activities. A few studies (cited above) recommended that UC patients are more vulnerable to develop colorectal cancer which helped us to determine that UC patients can also experience carcinophobia causing depression, aggression, and poor illness management.

Moreover, phobias and death anxiety were found to increase the level of physical and verbal aggression, anger and hostility among patients. Learned helplessness theory postulated that incurable diseases impaired patients' belief regarding will-power and self-efficacy and thereby this helplessness is linked to depression. ${ }^{29}$ In United Kingdom, researchers found that UC patients' lack of self-control was increasing the level of distress and anxiety. ${ }^{30}$ Thus, the current research specify that depression, phobias, aggression, and deteriorated self-efficacy infuse rigorously among UC patients.

Additionally, the current study carries few flaws like it was quantitative in nature, a detailed exploratory study can reveal multidimensional bio-psycho-social sufferings of UC patients. Data was not gathered across different age groups, 
cities, and ethnicities of Pakistan which could specify different aspects of the psychological co-morbidities among patients. So, further studies can be carried out to overcome these limitations.

Thus, the present study suggests that first of all, it is necessary to spread awareness regarding the triggering factors of UC to escape normal population from developing it as primary prevention is better than secondary prevention but for patients who have diagnosed with these problems, medical health care professionals should refer such patients to counselors or health psychologists. They can better help them to manage noncompliance with unpleasant medical procedures by reducing the depression level and phobias through relaxation exercises, cognitive behavioral therapy and pain management therapies.

\section{CONCLUSION}

UC patients manifest a range of psychological co-morbidities. Especially, fear of developing cancer and death anxiety, restrict patients to control symptoms, to manage role and emotional functioning and to communicate with doctors to get adequate treatment regimens. Therefore, the commencement of psychotherapeutic programs can be helpful for maintaining the psychological health of patients.

\section{REFERENCES}

I. Yanai H, Salamon N, Lahat A. Complementary therapies in inflammatory bowel diseases. Curr Gastroenterol Rep 2016;18(62). DOI: 10.1007/s | |894-016-0537-6.

2. Lohan C, Diamantopoulos A, LeReun C, Wright E, Bohm N, Sawyer LM. Tofacitinib for the treatment of moderately to severely active ulcerative colitis: A systematic review, network meta-analysis and economic evaluation. BMJ Open Gastroenterol 2019; 6(I). DOI: 10.1136/bmjgast2019-000302.

3. JairathV, Feagan BG. The global, regional, and national burden of inflammatory bowel disease in 195 countries and territories, 1990-2017: A systematic analysis for the global burden of disease study 2017. Lancet Gastroenterol Hepatol 2020;5(I): 1730. DOI: $10.1016 / 52468-1253$ (19)30333-4.
4. King D, Reulen RC, Thomas T, Chandan JS, Thayakaran R, Subramanian A, et al. Changing patterns in the epidemiology and outcomes of inflammatory bowel disease in the United Kingdom: 20002018. Aliment Pharmacol Ther 2020;5I(I0):922-34. DOI: 10.1III lapt.15701.

5. Misra R, Limdi J, Cooney R, Sakuma S, Brookes M, Fogden E. Ethnic differences in inflammatory bowel disease: Results from the United Kingdom inception cohort epidemiology study. World J Gastroenterol 2019;25(40):6I45-57. DOI: 10.3748/wjg.v25.i40.6I45.

6. Majeed S, Gohar F, Riaz M. Prevalence of inflammatory bowel disease and associated predisposing factors. Int J Appl Res 2018;4(2):208-I I.

7. Qureshi M, Abbas Z. Clinical presentation of ulcerative colitis in Pakistani adults. Euroasian J Hepatogastroenterol 20I5;5(2): 127-30. DOI: 10.5005/jp-journals|00|8-||15।.

8. Vaizey CJ, Gibson PR, Black CM, Nicholls RJ, Weston AA, Gaya DR, et al. Disease status, patient quality of life and healthcare resource use for ulcerative colitis in the UK: An observational study. Frontline Gastroenterol 2014;5(3):183-89. DOI: I 0.1 | 36/flgastro-20 I3-100409.

9. Brown SD. Ulcerative Colitis from patients' viewpoint a review of two internet surveys. Gastroenterol Nurs 20I2;35(I):54-63. DOI: 10.1097/ SGA.0b0 I 3e 3 I824 Id98 I

I0. Haider SI, Rasool I, Ahmed S, Hussein S, Hussein J, Hamirani MM. Frequency of depression, anxiety and stress in patients referred for endoscopy with symptoms of dyspepsia. J Liaquat Uni Med Health Sci 20 I 3; I 2(3): I 40-44.

II. Sajadinejad MS, Asgari K, Molavi H, Kalantari M, Adibi P. Psychological issues in inflammatory bowel disease: An overview. Gastroenterol Res Cent 20I2;20(I2). DOI: 10.1I55/20I2 $/ 106502$.

12. Olen O, Erichsen R, Sachs MC, Pedersen L, Halfvarson J, Askling J, et al. Colorectal cancer in ulcerative colitis: A Scandinavian populationbased cohort study. Lancet 2020; 395(| $02 \mid 8):|23-3|$. DOI: 10.1016 /SOI40-6736(I9)32545-0.
13. Choi K, Chun J, Han K, Park S, Soh H, $\mathrm{Kim} \mathrm{J}$, et al. Risk of anxiety and depression in patients with inflammatory bowel disease: a nationwide, population-based study. J Clin Med 2019; 8(5):654. DOI:10. 3390/jcm8050654.

14. Bannaga AS, Selinger CP. Inflammatory bowel disease and anxiety: links, risks, and challenges faced. Clin Exp Gastroenterol 2015;8: III-17. DOI: 10.2 | 47/CEG.S57982.

15. Khaliq SA, Gul A. Validity and reliability of Urdu version of beck's depression inventory among students of madaris (Islamic Institutes). Isra Med J 2018;10(3):175-6.

16. Berrenberg JL. The cancer attitude inventory: Development and validation. J Psychosoc Oncol 199|;9(2):35-44. DOI: 10.1300/J077v 09n02_03.

17. Boschen MJ, Veale D, Ellison N, Redell T. The emetophobia questionnaire (EmetQ-13): Psychometric validation of a measure of specific phobia of vomiting (emetophobia). J Anx Dis 20I3; 27(7): 670-77. DOI: 10.1016 /j.janxdis.2013.08.004.

18. Page AC, Bennett KS, Carter O, Smith J, Woodmore K. The blood-injection symptom scale (BISS): Assessing a structure of phobic symptoms elicited by blood and injections. Behav Res Ther 1997;35(5):457-64. DOI: 10. 1016/s0005-7967(96)00I20-9.

19. Saleem T, Gul S, Saleem S. Death anxiety scale; translation and validation in patients with cardiovascular disease. Professional Med J 20I5;22(6):723-32.

20. Gallagher JM, \& Ashford J. Buss-Perry aggression questionnaire: Testing alternative measurement models with assaultive misdemeanor offenders. Crim Justice Beh 2016; 43(II): I-30. DOI: I0.I I 77/00938548I 6643986 .

21. Riaz S, Haq N, Ahmed F, Nasim A, Tahir M, Khan MK, et al. Reliability and validity of Urdu version of the selfefficacy for managing chronic disease 6-item scale for patients with hypertension in Quetta, Pakistan. Asian J Res Med Pharm Sci 2017; 2(I):I-8. DOI: 10.9734/AJRIMPS /2017/37210.

22. Graff LA, Walker JR, Bernstein CN. Depression and anxiety in 
inflammatory bowel disease: A review of comorbidity and management, inflammatory bowel diseases. Inflamm Bowel Dis 2009; 15(7): I 105-18. DOI: 10.1002/ibd.20873.

23. Kochar B, Barnes EL, Long MD Cushing KC, Galanko J, Martin CF, et al. Depression is associated with more aggressive inflammatory bowel disease. Am J Gastroenterol 2018; I I3(I):80-5. DOI:I0.1038 lajg.2017.423.

24. Yanartas O, Kani HT, Bicakci E, Kilic I, Banzragch M, Acikel C, et al. The effects of psychiatric treatment on depression, anxiety, quality of life, and sexual dysfunction in patients with inflammatory bowel disease.
Neuropsychiatr Dis Treat 20।6; I 2:673-83. DOI: 10.2I47 /NDT.SI06039.

25. Connelly TM, Koltun WA. The cancer "fear" in IBD patients: Is it still REAL? J Gastrointest Surg 20I4; I8(I):2I3-8. DOI: |0.1007/s | |605-0|3-23 |7-z.

26. Wani AL, Ara A, Bhat SA. Blood injury and injection phobia: The neglected one. Behav Neurol 2014;2014. DOI:I0.II55/20|4/47|340.

27. McLenon J, Rogers AM. The fear of needles: A systematic review and meta-analysis. J Advanc Nurs 2018;75(I):30-42. DOI: I0.IIII /jan. 13818.

28. Falvey J, Greenwood R, Creed TJ, Smithson J, Sylvester P, Fraser A, et al.
Mortality in ulcerative colitis - what should we tell our patients? Threeyear mortality following admission for the treatment of ulcerative colitis: A 6year retrospective case review. Frontline Gastroenterol 20I0; I(I):35-4I. DOI: I0.II36/fg. 2009.000216

29. Nuvvula S. Learned helplessness. Contemp Clin Dent 2016;7(4):426-7. DOI: I0.4I03/0976-237X. 194124

30. Cooper JM, Collier J, James V, Hawkey C]. Beliefs about personal control and self-management in 30-40year olds living with inflammatory bowel disease: A qualitative study. Inter J Nur Stud 2010;47(12):1500-9. DOI: 10 $1016 / j . j$ ijnurstu.2010.05.008.

\section{AUTHORS' CONTRIBUTIONS}

Following authors have made substantial contributions to the manuscript as under:

GI: Conception and study design, analysis and interpretation of data, drafting the manuscript, approval of final version to be published

HS: Acquisition of data, drafting the manuscript, approval of final version to be published

Authors agree to be accountable for all aspects of the work in ensuring that questions related to the accuracy or integrity of any part of the work are appropriately investigated and resolved.

CONFLICT OF INTEREST
Authors declared no conflict of interest
GRANT SUPPORT AND FINANCIAL DISCLOSURE
NIL

This is an Open Access article distributed under the terms of the Creative Commons

Attribution-Non Commercial 2.0 Generic License.

\section{DATA SHARING STATEMENT}

The data that support the findings of this study are available on request from the corresponding author. The data are not publicly available due to privacy or ethical restrictions.

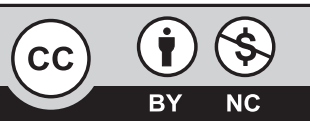

KMUJ web address: www.kmuj.kmu.edu.pk

Email address: kmuj@kmu.edu.pk 